\title{
Exploring Parliamentary Debate as a Pedagogical Tool to Develop English Communication Skills in EFL/ESL Classrooms
}

\author{
Eunice M. Aclan (Corresponding author) \\ University Research Center, Adventist University of the Philippines \\ Puting Kahoy, Silang, PO Box 1834, Cavite 4118, Philippines \\ E-mail: nice_aclan@yahoo.com \\ Noor Hashima Abd. Aziz \\ School of Education and Modern Languages \\ Universiti Utara Malaysia, Sintok, Kedah 06010, Malaysia \\ E-mail: noor934@uum.edu.my
}

Received: 18-07-2014

doi:10.7575/aiac.ijalel.v.4n.2p.1

Accepted: 19-09-2014

Published: 01-03-2015

URL: http://dx.doi.org/10.7575/aiac.ijalel.v.4n.2p.1

\begin{abstract}
To survive in the $21^{\text {st }}$ century workplace, communication skills are extremely important. However, a mismatch between the industry requirement and the university graduates' competencies in terms of effective communication skills exists. Rote learning and lack of opportunities to practice English communication skills inside and outside the classroom are common issues in EFL/ESL contexts. Thus, this qualitative study was conducted to explore how debate as a pedagogical tool with three stages - pre-debate, actual debate and post-debate - can develop communication skills. The data were gathered through semi-structured one-on-one interview with five debate experts across from ASEAN countries and focus group interview with six ASEAN debate students. The participants of this study described the use of the pre-debate stage for the research and brainstorming tasks that engage the team members with each other, the actual debate for the arguments, POI and rebuttals that actively engage debaters with their opponents, and the postdebate stage that engage all the debaters with the adjudicators, their team-mates and their opponents. This pedagogical aspect focusing on the three stages of debate which has implications for SLA and language teaching was not substantially dealt with in previous studies on debate.
\end{abstract}

Keywords: pedagogical tool, English communication skills, All-Asians parliamentary debate

\section{Introduction}

\subsection{Background of the Problem}

The highly competitive $21^{\text {st }}$ century knowledge economy has placed a more pressing demand for graduates who can communicate well in English. Globalization and fast-paced technological advancements necessitate collaboration of people across geographical locations. For example, a team of engineers in Malaysia can work virtually with a consultant in Europe or a business executive in Thailand can carry out her business with her clients in the ASEAN region via online or overseas communications. These scenarios are made possible with the use of English as an international language. Thus, developing countries including China, now a major world economy, are strengthening the teaching of English. In fact, Anwei Feng, author of the book, English Language Education across Greater China, said, "English proficiency has become a highly valorized form of cultural capital with strong exchange value in China. A lot of privileged jobs and lifetime opportunities depend on how successfully you did in your English tests in universities" (Clavel, 2014, para. 17-18). Even the ASEAN Economic Community (AEC) which will open business and job opportunities within the region next year will not be successful without a common language. Therefore, member countries are trying to improve the English proficiency of their citizens. However, there is a need for English teaching pedagogies that work well with EFL/ESL students to be explored and introduced in the classroom to make graduates more effective in communication skills.

In the Philippines, a study by People Management Association of the Philippines (PMAP) found that four out of ten new graduates who sought for a job were not hired because they lacked key competencies such as effective communication skills and critical thinking (Rosero, 2012). PMAP Director for Academe-Industry Linkages, Gigi Alcasid, stated that each industry would have some sort of minimum standard. Alcasid said that the study showed that 40 percent of fresh graduates do not immediately get hired because of the deficiencies in soft skills including communication skills.

In terms of English proficiency, Thailand ranked near the bottom, $55^{\text {th }}$ out of 60 Asian countries whose mother tongue is not English in a survey conducted by EF Education First (The Nation, 2013, November 7). The English proficiency 
country rankings are based on tests given to 750,000 adults from 60 countries in 2012 . The author of this news article said that this report shows "the persistence of one of the key competitive weaknesses of the Thai economy" (para. 1).

Research shows that the lack of communication skills is not found only in Thailand, the Philippines and Malaysia but it has become a phenomenon in other developing countries in Asia. In the study of Birrell (2006, as cited in Shakir, 2009), with 12,000 foreign students at Monash University in Australia, over one-third of this number including 23.5 percent Malaysians had low English proficiency, leading the researcher to conclude that even if these students were good at work ethics they would not be good enough for work at the professional level. Shakir (2009) partly blames this phenomenon to rote learning, the lack of meaningful activities that involve critical thinking.

Debate as an ancient teaching method used by Greeks 4,000 years ago (Darby, 2007) has been widespread as an extracurricular activity usually in the form of competitions (Akerman \& Neil, 2011). Debate is one of the co-curricular activities along with sports mentioned by Sulaiman,Fauziah, Wan Amin \& Nur Amiruddin (2008) to develop soft skills in Universiti of Malaysia Terengganu. Sulaiman et al claim that the preparation and delivery of arguments in debates give students the chance to develop their communication skills, self confidence, research skills and critical thinking. However, debate, "the process of inquiry and advocacy, a way of arriving at a reasoned judgment on a proposition" (Freeley \& Steinberg, 2012, p. 6), is more known as a competitive activity not only in Malaysia, the Philippines and Thailand but all over the world (Akerman \& Neale, 2011; Parcher, 1998; Snider \& Schnurer, 2006; Yang \& Rusli, 2013).

Despite the benefits of debate in the classroom particularly its potential to develop communication skills, teamwork and critical thinking skills, the top skills identified in the study by Darby (2007), Goodwin (2003), Hall (2011), Kennedy (2009) and Musselman (2005), debate is not yet widely introduced in the classroom. All of these previous studies were conducted in an English-speaking country. Bellon (2000) and Akerman and Neale (2011) found that if debate is used in the non-English speaking context, it can improve the communication skills of students in English but they recommended that more studies in the EFL/ESL context need to be done. Thus, this study was conducted to fill in this gap. If debate is limited to advantaged students joining in debate tournaments as an extracurricular activity given the host of soft skills the literature said debate can develop, very few students would benefit from it. Furthermore, most of the previous studies used quantitative and mixed methods which limited the understanding of how debate can develop communication skills. Therefore, this qualitative study provides a thick description of how debate as a pedagogical tool can develop soft skills in the English as a foreign language (EFL) or as a second language (ESL) classroom.

Pedagogy, known as the science of teaching, is defined by Hardman (2008) as "a structured process whereby a culturally more experienced peer or teacher uses cultural tools to mediate or guide a novice into established, relatively stable ways of knowing and being within a particular, institutional context, in such a way that the knowledge and skills the novice acquires lead to relatively lasting changes in the novice's behavior, that is, learning" (p. 65). The Activity Theory by Vygotsky, Leontiev and Ergestrom (Hardman, 2008) considers all the parts of the whole activity to lead the student to lasting changes, which is learning. Related to this concept are Brown's (2007) proposition that pedagogical tasks should resemble real-life needs outside the classroom and Bloom's Taxonomy that all teaching objectives should include higher order thinking skills, i.e. analyzing, evaluating and creating. In addition, the strong version of Communicative Language Teaching (CLT), which is letting the EFL/ESL students use English to learn English in a communicative way in order to develop their communication skills (Howatt as cited in Richards \& Rodgers, 2001) is espoused in this study. Thus, debate was introduced to EFL students in this study to learn English communication skills instead of just having them listen to recorded dialogues or conversations most of the time, pronunciation drills, games or ticking listening activity sheets without progressing to real communication.

Fluency, accuracy and complexity can be developed by giving language learners meaningful input to naturally develop their receptive competence as Krashen (1987) claims. However, Richards (2008) points out that, "this is not always confirmed in the experience of learners, who often find that productive skills are well below the level they would like them to be, despite reasonably good comprehension skills" (p. 4). Thus, this study takes the stand that learners need to use language appropriately in communicative contexts by deliberately making them communicate through communication tasks in order to learn the language and develop communication skills. This stance is in consonance with Ellis's (2003) proposition which criticizes the Present-Practice-Produce (PPP) language teaching procedure. He points out that SLA research has shown that language learners do not acquire language in this kind of teaching. Instead, Ellis (2003,) believes that:

They [learners] construct a series of systems, known as interlanguages, which are gradually grammaticized and restructured as learners incorporate new features... It is not easy to design tasks that require learners to use targeted structure, as learners can always fall back on their strategic competence to circumvent it... One way out of this problem is to make it clear to the learners that they must use the targeted structure when they perform the task. However, this would encourage the learners to focus primarily on form with the result that the task ceases to be a task... (p. 29)

The option presented by Brumfit (1979, as cited by Ellis, 2003) can be a practical basis of this study. As in the case of debate, for example, the students have to present first, then the teacher and/or a team of commentators who also serves as adjudicator or judge takes notes and/or records the strengths and weaknesses of the debaters. In this study, recording 'matter' or content and 'method' of debating as well as 'manner' covering language use errors such as grammar, vocabulary, pronunciation, transitional markers and other linguistic components will be done. As the main focus of the task is to make students achieve fluency and complexity, accuracy is set aside but not totally ignored. Rather, it has its 
proper place in order to avoid fossilization of errors, which is a major concern in CLT or Tasked-Based Language Teaching (TBLT) that Richards (2008) wanted to be addressed. This position is seen to be working well with EFL students as students are given the autonomy to produce communicatively and address their mistakes at the end of the activity so they are not disrupted during the activity. If debate is introduced in the EFL/ESL classroom, more students will benefit from debating, i.e. the development of multiple soft skills particularly English communication skills and critical thinking and problem-solving skills.

Pedagogical tasks should be structured to provide learning opportunities for the refinement of knowledge and should be based on learning principles that students use authentic language (Richards \& Rodgers, 2001). This is how debate as a pedagogical tool in a microcosm of tasks in various phases of the activity is conceptualized in this study with the goal of developing students' multiple soft skills although in this paper is limited to communication skills students direly needed to survive in the global workplace. The three stages of debate, i.e. pre-debate, while-debate and post-debate (Darby, 2007), will be the focus of analysis in this study. Using the All-Asians Parliamentary Debate (APD) format whose special feature is the raising and answering of Point of Information (POI) was not explored in the previous literature as to how it can develop soft skills. Therefore, the purpose of this study is to explore how debate as a pedagogical tool with three stages can develop communication skills in English. The major contribution of this study comes from the participants' experience on how they improved their English by debating thus this study's findings may have practical implications in the field of second language acquisition (SLA) and language teaching leading to the introduction of debate as a pedagogical tool to develop language proficiency in the EFL/ESL classroom.

\subsection{Importance of the Problem}

This study is important in that second language acquisition (SLA) and language teaching was not covered in the previous studies on debate used in the classroom. Debate activities in the literature were mostly competitive usually for advantaged students in native English speaking countries. Although there were a few studies using debate in the classroom, they were mostly done in English-speaking countries like in the USA such as those by Darby (2007), Goodwin (2003), Hall (2011), Kennedy (2009) and Musselman (2005). Goodwin's study Furthermore, although Yang and Rusli's (2012) study was conducted in an ESL-context in Singapore, they used mixed-method like most of the studies conducted with debate students in the USA and they used various debate formats. This study used qualitative method to explore how All-Asians parliamentary debate format used as a pedagogical tool with three stages to develop soft skills from the perspective of debate experts who have been teaching debate and who used to be debaters. As this study deals with pedagogy, analysis focusing on each debate stage is important. Studying the entirety of the debate as a pedagogical tool by examining its parts to deeply understand it was not dealt with in the previous studies. The in-depth and rich description of the debate experts' experience triangulated by EFL/ESL debate students will provide a better understanding of how debate can develop communication skills.

\subsection{Relevant Scholarship}

There is limited research on using debate in the classroom such as those by Goodwin (2003), Hall (2011), Kennedy (2009), Musselman (2004), Roy and Macchiette (2005) and Yang and Rusli (2012). However, there is no substantial description of how debate can develop communication skills particularly in English, which is the highlight of this present study as all these studies except Yang and Rusli's were conducted in native English-speaking countries. Although Yang and Rusli's (2012) study in Singapore, an ESL context, found out that debate as a pedagogical tool can develop communication skills, it did not describe how communication skills can be developed. Goodwin (2003) used end-of-course essay-type assessment to capture her students' perspective on debate exercises in content area classes. Goodwin presented qualitative findings that describe debate as an excellent small group task as each team member benefited from the peers' equal distribution. Although Goodwin's study was conducted in the USA, a native-English speaking country, her participants reported that the preparation stage of the debate gave them the best opportunity to listen to each other and they said that, "the real learning happened in the discussion" (p. 160). This finding contributed to the conceptualization of this reported study in that the researcher extended the use of debate to the EFL/ESL context and further developed it to critically examine not only the pre-debate and actual debate but also the post-debate stage which was not given attention in past studies.

The study of Inoue and Nakano (2004) in Japan compared the US National Debate Tournament (NDT) and the British Parliamentary (BP) format, which also allows debaters to actively interact with each other through the Point of Information or POI, is related to the All-Asians Parliamentary (APD) used in this study. The main difference between $\mathrm{BP}$ and APD is that, the former has four speakers on each side while APD has only three and BP is also more complicated as each side has two teams making both sides four teams while APD has only two teams against each other. Inoue and Nakano's study was also conducted in the EFL context but it focused on competitive debating. Nevertheless, it found out that BP is perceived by the respondents to develop English communication skills. As to how it can develop English communication skills, it was beyond the scope of the study as it mainly asked the participants to identify three benefits, motives and disadvantages of their competitive debate participation. Inoue and Nakano's study served as a springboard for this reported study in that it was conducted in an EFL context and used parliamentary debate. However, it used competitive debate which means it involved more language proficient students making the use of BP more appropriate while this present study extended it to the classroom setting using APD, a simpler debate format fit for beginning debaters. APD was chosen so that students can focus more on the development of soft skills particularly communication and argumentative skills rather than on dealing with the complexity of the debate format. In the BP format, even if the two teams with two members each are on the same side, they consider each other as 
adversaries so one team has to compete with three teams for every debate round, two teams are on their opposite side and the other on the same side. This makes it complicated for classroom debating with mixed language proficiency students usually elementary, thus APD is more appropriate for this study.

\section{Method}

This section presents the methodology on how the study was conducted. This study used qualitative research case study design. It used two methods of data gathering, namely focus group interview and one-on-one interview. These methods were utilized to ensure the study's quality and trustworthiness specifically credibility, dependability and confirmability of the findings. To achieve transferability as one of the measures to establish the trustworthiness of this study, thick description of analysis and interpretation of the data as well as the sampling methods and procedures of the study was done. In this study, purposive sampling with set criteria was used in order to achieve the study's purpose, i.e. to explore how All-Asians Parliamentary Debate as a pedagogical tool with three debate stages - pre-debate, actual debate and post-debate - can develop communication skills. The maximum variation criteria include diversity of participants representing various countries in the ASEAN region with EFL/ESL contexts.

\subsection{Research Design}

This study used qualitative methodology. Qualitative research as a field of inquiry has been defined in many different ways. Denzin and Lincoln (2005), focusing on the context and data collection, offer the following definition. "Qualitative research is a situated activity that locates the observer in the world...This means that qualitative researchers study things in their natural settings, attempting to make sense of, or to interpret, phenomena in terms of the meanings people bring to them" (p. 3).

As an in-depth understanding of how debate as a pedagogical tool can develop soft skills in the EFL/ESL context, qualitative case study research design is appropriate. According to Hancock and Algozzine (2006), case study would "allow researchers to capture multiple realities that are not easily quantifiable" (p. 72). Furthermore, Yin (2003 as cited in Baxter and Jack, 2008) said that qualitative case study enables the researcher to answer "how" and "why" questions. Baxter and Jack (2008) pointed out that qualitative case study takes into consideration how a certain phenomenon is influenced by the context within which it exists. The holistic approach using purposive sampling techniques in natural setting makes case study different from other methods. This study addresses multiple realities and issues that cannot be explained in quantitative terms, thus qualitative case study is the appropriate approach wherein data were gathered from participants purposively chosen for the data gathering of their insights and perspectives from their actual debating and debate coaching experiences. To fill in the gap of what is not fully known in the literature on debate from the debate experts' perspective, triangulated by the EFL/ESL students' perspective, in-depth and rich description on how each debate stage can develop soft skills was made possible through qualitative case study method.

\subsection{Participant Characteristics}

Since this study deals with pedagogy, the key participants are debate experts who have been teaching debate either in classroom or in competition using the All-Asians Parliamentary format for at least two years. The five debate experts also have prior debating experience before they became debate trainer, coach or teacher in the EFL/ESL context particularly the ASEAN region making them more experienced and knowledgeable in debate. Two of the debate experts are from Malaysia (ESL), one from the Philippines (ESL) and two from Thailand (EFL).

Table 2.2.1 Demographic Profile of Debate Experts

\begin{tabular}{ccccc}
\hline Debate Expert & Country & $\begin{array}{c}\text { Number of Years } \\
\text { Debating }\end{array}$ & $\begin{array}{c}\text { Number of Years Teaching } \\
\text { Debate/Coaching Debaters }\end{array}$ \\
\hline 1 & Job & Thailand & 6 & 4 \\
2 & Eric & Philippines & 4 & 10 \\
3 & Prasit & Thailand & 5 & 6 \\
4 & Joyce & Malaysia & 3 & 2 \\
5 & Sonya & Malaysia & 4 & 3 \\
\hline
\end{tabular}

To triangulate or validate the perspective of the debate experts, a focus group (FG) of six ASEAN students from the debate class in a university in north Malaysia was formed. The FG participants took debate as a Listening and Speaking course taught intensively for four months, four times a week at 1.5 hours per day. Coming from various countries in the ASEAN region, i.e. Thailand, Myanmar and Indonesia, the participants have limited opportunities using English. All of them scored far below the minimum English proficiency entrance requirement in western universities which is usually $500-600$. Their average institutional TOEFL (ITP-TOEFL) score is 391, categorized as elementary. No one was from the intermediate (450) or higher level. However, these students scored high in both their listening and speaking entrance tests thus they were placed in the debate class, instead of the normal conversation classes in the lower levels of the preuniversity program. Two of them are females and four are males. Criteria set in selecting the participants of the focus group include representational samples, namely students who have experienced classroom debate from various countries in the ASEAN region with EFL/ESL background and from both genders - male and female. Table 2.2.2 shows the demographic profile of the focus group participants. 
Table 2.2.2 Demographic Profile of the Focus Group Participants

\begin{tabular}{|c|c|c|c|}
\hline $\begin{array}{c}\text { Focus Group Participants } \\
\text { (Pseudonym) }\end{array}$ & Gender & Country & $\begin{array}{c}\text { Entrance } \\
\text { ITP- } \\
\text { TOEFL } \\
\text { Score }\end{array}$ \\
\hline Nisa & Female & Thailand & 353 \\
\hline Intan & Female & Indonesia & 387 \\
\hline Мyo & Male & Myanmar & 417 \\
\hline Kittipat & Male & Thailand & 420 \\
\hline Chatri & Male & Thailand & 393 \\
\hline Andre & Male & Indonesia & 377 \\
\hline
\end{tabular}

While the debate experts come from both ESL and EFL contexts, the focus group interview participants in this study are all from EFL context in the ASEAN region. Using separate groups of individuals in a case study is supported by Creswell (2012) although the main purpose of the representation is not to generalize but to gain a better understanding of each represented case so that the various contexts that would be richly described in the findings would increase the transferability to the readers who will be using this study.

\subsection{Sampling Procedures}

Purposive sampling was used in this study specifically maximum variation sampling to capture and describe the central themes or principal outcomes on how communication skills in English can be developed by debating from the experience of the various participants across the ASEAN region. According to Patton (1990), "any common patterns that emerge from great variation are of particular interest and value in capturing the core experiences and central, shared aspects or impacts of a program" (p. 172). For a qualitative case study, purposive sample will be drawn to build a variety of perspectives from different samples and acknowledge intensive study opportunities (Stake, 2005). Stake emphasizes that "nothing is more important than making a representative selection of cases" (p. 451). These representatives should be carefully chosen to increase the scope and richness of data, particularly from multiple perspectives as suggested by Rudestam and Newton (2007). In this case, formal sampling was necessary which entailed identification of criteria.

Criteria were set in the selection of the key participants, the debate experts. These included prior debating experience and at least two years of debate teaching or coaching experience using the All-Asians Parliamentary Debate (APD) format in the EFL/ESL context. Selection also considered both genders, male and female, and at least three countries from the ASEAN region for richer data. For the focus group, the debate students, selection included from at least three different ASEAN countries in ESL/EFL context with at least one semester of classroom All-Asians parliamentary debating experience, from three different intakes and from both genders.

The number of samples desired for the one-on-one interview was two for each four ASEAN countries including Indonesia. However, at the initial interview, it turned out that the other two who agreed to be interviewed in the Philippines have taught British Parliamentary (BP) format instead of All-Asians format. The same with those contacted in Indonesia revealed that they used BP in teaching debate, thus they were eliminated so that only five who fit in the criteria who agreed to interview became the key participants of this study.

For the focus group interview, Krueger (2004) suggested three groups but because of the limitation of the study set in the ASEAN region, there were only eleven ASEAN students within the three intakes that debate was offered in the locale of the study. Although eight confirmed to participate in the interview, only six students participated in the actual interview. Nevertheless, the focus group interview conducted with students served as minor source of data, i.e. for triangulation. Besides, a small number, like three to five participants, according to Creswell (2012) and Tracy (2013), is more manageable especially if confusion is to be avoided with the identification of the speakers and with the transcription and analysis of data. Too many participants may confuse the transcriber of the data.

In qualitative inquiries, the best sources of data are those who have experienced the phenomenon (Creswell, 2014). Although there were only five key participants in this study, they provided rich data as they are all experienced debaters who are used to supporting, explaining and substantiating their points extemporaneously. The saturation of the data desired to be achieved to answer the research questions of this study was already reached even on the third participant when redundancy of data was observed. Data saturation is an important factor to consider in data gathering and this is achieved when the participants say almost the same thing and any new data will no longer make a difference (Creswell, 2012; Patton, 1990; Rudestam \& Newton, 2007; Tracy, 2013).

\subsubsection{Data Gathering Techniques and Procedures}

The major data gathering method for this study was the semi-structured one-on-one interview (OOI) with the five debate experts. As suggested by Hancock and Algozzine (2006), the researcher should identify key participants whose background, experience and opinions will provide relevant information and insights related to the research questions. In the case of this study, debate experts who did not only debate but have taught debates were the main sources to answer the research question posed in this study. 
Although time-consuming and costly, one-on-one or individual interview may yield significant information in breadth and depth from the individual participant's perspective (Creswell, 2012; Hancock \& Algozzine, 2006). The one-on-one interview was properly set using a semi-structured interview guide allowing flexibility. Probes and follow-up questions were raised in cases where the prepared questions were not satisfied as suggested by Creswell (2012). The OOI lasted for an average of one hour 25 minutes. It was audio-taped for higher fidelity and trustworthiness (Rudestam \& Newton, 2007).

In conducting the focus group interview (FGI), the participants understood and signed the Letter of Consent and they also provided their demographic information first. Then, they were explained the conduct of the interview, the approximate duration of the interview and that they should elaborate their answers in details as much as possible. They also understood that probes or follow up questions would be asked further at the course of the interview.

Each of the participants took turns in answering the questions unless they declined a turn or volunteered for extra or further answers. This helped create a more relaxed and friendly atmosphere. Allowing participants freedom in volunteering and declining to answer was intended to reduce tension or pressure and to increase the richness and depth of data (Krueger, 1994). Creswell (2012) points out that FGIs are advantageous if participants will likely yield the best data through their cooperation with each other and with the group members' similarity.

The FGI which lasted for one hour forty two minutes was audio-recorded for high fidelity (Rudestam \& Newton, 2007). Qualitative research is not centered on the rules but on the rigors of trustworthiness to achieve quality (Krefting, 1991) and recording or videotaping is one way of ensuring rigor.

\subsubsection{Ensuring Trustworthiness}

Guba's (1981, as cited in Krefting, 1991) model of trustworthiness consisting credibility, transferability, dependability and confirmability was used to address the issues of validity, reliability and objectivity in this qualitative study. Guba proposes this model to assess the quality and trustworthiness of qualitative data and increase the rigor of the study's results particularly for readers to evaluate the findings as they construct meaning and relate it to their own context.

To ensure the key strategy, credibility (or internal validity in quantitative approach) in this study, four strategies, i.e. triangulation, peer-debriefing, member check and appropriate interpretation (Krefting, 1991), were employed both in the gathering and interpretation of data. As these are basic strategies in the conduct of qualitative research to ensure trustworthiness, the terms are defined and explained by Creswell $(2012,2013)$ and Rudestam and Newton (2006) as follows.

Triangulation is the solicitation of data from various and multiple sources in order to cross check and corroborate evidences that may shed light on the theme or theory of the study. In this study, various sources of data include one-onone interview with debate experts of different nationalities and backgrounds as well as focus group interview with debate students from various ASEAN countries and intakes.

Peer debriefing or peer review makes use of colleagues or peers to play the roles of devil's advocate who will ask critical questions related to data gathering, data analysis and interpretation to ensure the credibility or honesty of the researcher. In this study, aside from the supervisor's critiquing and giving feedback to this study, a work colleague played as a devil's advocate. She gave feedbacks on the data gathering questions for both one-on-one and FG interviews. Then later, she was also asked to critique on the data analysis and interpretation so that credibility would be ensured.

Member check is returning to the participants to present to them the whole narrative script as well as the interpretations by the researcher in order to confirm the accuracy and credibility of the results. In this study, the participants were informed ahead of time that they would be asked to confirm on the accuracy of the transcripts of the interview as well as the interpretation of the data.

Interpretation in qualitative research, according to Creswell (2012), "means that the researcher steps back and forms some larger meaning about the phenomenon based on personal views, comparisons with past studies, or both" (p.257). He adds that qualitative research is interpretive thus the researcher should make sense of the results of the study. Boeije (2010) explains that findings are the "outcomes of the researcher's analytical activities (not the activities themselves) and consist of data and everything the researcher makes out of them, whether descriptions, theoretical models or explanations" (p. 196). In this study, the data were interpreted in the light of previous studies, theories and the researcher's personal views.

Creswell (2012) emphasizes three ways to validate the accuracy of qualitative research findings: triangulation, member check and auditing. By audit, Creswell refers specifically to external audit in which the researcher seeks an expert to review different aspects of the research including the strengths and weaknesses of the study. All these three ways of validating accuracy by Creswell (2012) were employed in this study to ensure rigor and trustworthiness.

\subsubsection{Ethical considerations: Confidentiality and Informed Consent}

The participants in this study were on voluntary basis and were asked to sign a written informed consent letter. The focus groups as well as the individual interviewees decided on the schedule when they were free and convenient to be interviewed. They were briefed of the purpose and nature of the study and were assured that there would be no harms or risks in participating in this research. They were also informed that confidentiality and anonymity would be strictly observed as pseudonym would be used instead of their name to protect their identity. 


\section{Findings and Discussion}

In this section, the results of the study are summarized. To answer the Research Question, "How can debate as a pedagogical tool with three stages, i.e. pre-debate, actual debate and post-debate, develop communication skills in English?" the perspective of the debate experts are presented first then triangulated by the perspective of the debate students. Although the participants of this study described how the soft skills in the Malaysian Soft Skills Development Module (MSSDM) can be developed in each stage of the debate, this paper limits the presentation of results to communication skills. To ensure the trustworthiness of the findings, i.e. to provide evidence of the interpretation, verbatim excerpts from the participants are presented in narrative form. Emergent themes are deduced from the data as shown in subheadings for each of the three debate stages.

Communication skill is a top soft skill identified by all the participants of this study with the actual debate, but participants are not consistent of its importance in the pre-debate stage. It is described by the participants of the study how it can be developed in each stage of the debate. Some participants portray its minor role while some consider it highly important in the pre-debate stage. Such inconsistency across sources of data should not be viewed as weakening the evidence but as an opportunity to explore the data's deeper meaning (Patton, 2002).

\subsection{How Debate Develops Communication Skills in the Pre-debate Stage}

The participants explained how communication skill is used and developed during the preparation stage of the debate. Two themes emerged from the data describing how debate can develop communication skills in English at the predebate stage, i.e. coherence through interaction and collaboration and acquisition of new ideas and vocabulary.

\subsubsection{Interaction and Collaboration to Achieve Coherence}

Job emphasized the need for coherence during the actual debate and for him, it can be achieved only through proper communication during the pre-debate stage.

Debaters have to talk to each other to make sure that they come across their ideas very well. Otherwise, they may not have enough coherence during the actual debate. Because if they lack this very important skill during the pre-debate task they might end up not having a parallel set of arguments during the actual debate which is actually happening. Because there are teams that are good speakers, they are good in analysis. It is that during the pre-debate task, they do not discuss properly what their arguments should be. And then they come up on the stage with different arguments or different focus and in the end they lose because the judges also try to see whether their arguments are coherent or not, which is part of the judging, which is the method on how they present their arguments.

Like Job, Sonya explained the necessity of communication during the preparation time. For her, communication at the pre-debate stage means interaction and collaboration primarily to share ideas in order to achieve what Job refers to as parallel or coherent arguments of the team.

Obviously, communication is also necessary during the prep time of the debate. How can debaters prepare without communicating with each other? As a team, we need to interact so that we can solve the problem, to collaborate, to share or to contribute our ideas and this means we use our communication skill.

This point about necessary interaction in order to prepare for the actual debate is what makes debate highly communicative. The debate preparation process itself necessitates natural communication to take place particularly for Sonya who handles international students who need to use English in order to understand each other. Thus, the brainstorming during the pre-debate stage offers a great opportunity to practice communication skills in English as they do not only talk to each other but they also read a lot and outline or write their speech. The perspective of the debate experts is triangulated by Kittipat, a debate student from Thailand. Kittipat mentioned a new point about the importance of a leader with good communication skills not given by any of the debate experts. Kittipat stated:

For me, the pre-debate stage, aside from what they already said, can develop communication skills. For the team to prepare well, they [must] need to communicate to each other for what to prepare. The one to act like a leader should have very good communication skills so the team members will understood [understand] what to prepare.

Kittipat highlighted one of the three fundamentals of effective leadership, i.e. communication skills given by John Ryan (2009), the president of Center for Creative Leadership and former chancellor of State University of New York. Kittipat also featured the nature of debate being a team activity that requires collaboration making it fit well in the CLT and task-based language teaching paradigms as learners need to talk to each other at the pre-debate stage in order to solve a problem.

\subsubsection{Acquisition of New Ideas and Vocabulary through Reading}

Sonya also shared interesting points how debating can develop communication skills during the preparation stage of the debate. She described a very important pedagogical aspect of learning English in her statements below.

In the preparation for the debate, I need to read a lot and reading also not only increase my knowledge or my ideas but I also improve my vocabulary. Because when I read, I get lots of new information and meet new words and I try to remember the new words. I write the new words I learn and try using them during the debate and even after the debate. And this works very well for me to improve my English and my communication skills because I can say exactly what I mean with the right words. 
Sonya's improvement in communication skills particularly from reading and specifically her gaining of ideas to talk about and vocabulary by the necessity to research prior to debate is also confirmed by Kittipat. As an EFL student who has a very limited opportunity of using and practicing English back in his country in Thailand, Kittipat attributes his learning of unfamiliar and difficult words in English to his debating experience even if it is only for one semester.

If you are assigned a certain topic, you need to read a lot. In debate, especially when we were given academic topics we never knew before, we have to research a lot. By reading a lot, we got a lot of information[s] and new words, new vocabulary to improve our English. To debate well, we need the right words to say so by researching before the debate, we try to remember the new ideas and the new words that we read and say it [them] when we debate. Actually, it's in debate I learn most of the hard words in English I know now because I am forced to read something that I never read before.

Reading as one of the macro-skills of communication is described by Sonya and Kittipat as one of the necessary aspects of the pre-debate stage and they attributed a great improvement of their vocabulary by debating. Vocabulary is necessary not only in reading but also in speaking, listening and writing. According to Wilkins (1987), "without grammar very little can be conveyed, without vocabulary nothing can be conveyed" (p.135). Indeed, vocabulary is very basic in all the four macro-skills. Sternberg (1987) said that it is common knowledge that people learn most of their vocabulary by reading. Furthermore, Krashen (1993) stated, "reading is good for you. Research supports a stronger conclusion, however. Reading is the only way, the only way we become good readers, develop a good writing style, an adequate vocabulary, advanced grammar, and the only way we become good spellers" (p. 23). Like Krashen (1993), Hadley (2000) believes in contextualized language learning and teaching. In debate, the unfamiliar words are used in context that facilitates learning. Remarkably, Sonya writes the new words she learns and uses them during the debate in context. Learners gain new knowledge more effectively if they are used in context. Thus, both new information and unfamiliar vocabulary add to the confidence of students to use the language when they debate.

In terms of how debate can help with writing, Andre reported that, "Debating helped me not only with my speaking and listening but also in reading and writing. Obviously, we have to speak and listen a lot and, of course, read a lot before the debate. But for writing, it helps me to quickly organize my ideas and support my points with evidences to make it [them] strong. Also I gain a lot of ideas and words by debating that can help me a lot when writing." The participants also said they have to remember not only the ideas but also the new words they have learned to be more effective in delivering their speeches as they always have the motivation to win and not to be embarrassed if they know what to say. The finding of this study is related to the Input Hypothesis by Krashen (1987) that once learners are exposed to comprehensible inputs, they acquire those and incorporate them with their interlanguage system. This is also supported by the Noticing Hypothesis of Schmidt (1986, as cited by Richards, 2008) that for learners to acquire new forms from input, it is necessary to notice such forms in the input. If the students are conscious in gaining more words to add to their repertoire or improve their grammar, for example, they notice unfamiliar words and grammar structures.

\subsection{The Actual Debate Stage}

Communication skill is considered as important as critical thinking and problem-solving skill at the actual debate stage by the participants of this study. Being the most important skill developed at the actual debate stage, it has the most themes that emerged from the data.

\subsubsection{Talking at the Level of the Judges and the Audience}

Job, Expert No. 1, who has been declared as one of the Top 10 Adjudicators in the European Union-Thailand Intervarsity Debate for two consecutive years now, explained:

During the debate task, obviously it's the communication skill that is given highlight because they [students] have to be able to effectively discuss the analysis, their own analysis in their arguments. Because no matter how good they are during the preparation stage if they cannot be able to relate the information or doing it clear to the set of judges then they will still not win. Therefore, communication skill is very, very important.

Job presented the relationship between the pre-debate stage and the actual debate stage. He showed how important the pre-debate stage is in terms of the preparation of arguments but he depicted how crucial it is for debaters to deliver their arguments for them to be clearly understood.

From the following excerpt, Job shows the importance of considering the audience when speaking.

Another thing that should be given emphasis here is how they are able to relate their information not just in the level of the judges but also in the level of the audience because they are the ones to understand what the debate is all about. Because there are debaters who are very good in the technical aspect of the debate, they are also good in digging deeper into every aspect of the argument or every issue that's being talked about but they are not able to communicate effectively...because they cannot talk at the level of the audience or the level of the judges. In one of the criteria of judging or one of the rules of judging is that the judges are average reasonable person. And if they're not able to communicate well to the judges as average reasonable person they might end up not winning at all. They might just be talking about the technicalities and stuff and then still they end up not winning. That's why communication skill is very important.

Furthermore, Job emphasized the importance of effective communication by considering the audience when debaters deliver their speech during the debate. It is indeed quite important because the adjudicators or judges and the audience in the debate are considered as average reasonable people, not experts of the topics the debaters are dealing with. 
Therefore, the debaters are required to convey and explain their arguments clearly so that the average judges and audience would understand.

Job's point of view on communication skills as the most important soft skill developed during the actual debate as well as his point on communicating to the judges is supported by Prasit's perspective. However, in the following excerpt, Prasit adds the dimension of the audience, not just the adjudicators and the hearers of the debate but also the opponents and the team-mates.

The first skill necessary or essential during the actual debate is communication skill. During the debate, you have to communicate with your opponents and with your team-mates in order to be intact on what you say against your opponents. So basically you have to communicate or talk. In your speech, you have to make the adjudicators understand what you convey so that's how you develop communication skills.

Indeed, when a debater delivers his or her speech, everyone listens. The opponents listen because they need to engage by raising a Point of Information, either a question or a statement, to weaken a given strong point. They can also show engagement through the rebuttal when it is their turn to speak. The team-mates also need to listen so that they would not repeat the same points said by their team-mate speaker or so that they can support his/her points when it is their time to speak. This feature of debate makes it a perfect pedagogical tool because it integrates reading, speaking and listening. The criteria for judging and the debate rules require debaters to engage with their opponents and collaborate with their team-mates.

\subsubsection{Communication Skills and Critical Thinking: Inseparable Skills in Debate}

Among the host of skills developed by debating aside from communication skills is critical thinking, a very important skill in this highly competitive knowledge economy. Job portrayed above the inseparable function of communication skill and critical thinking and problem-solving skill (analysis of arguments) when debating. This connection between communication and critical thinking skills is also described by Myo, a debate student from Myanmar in the following excerpt.

Communication skills and critical thinking skills can be developed during the debate. Because like me before, I would close my eyes to remember what I memorized before the debate. But this is not good because if we debate, we interact with our opponents. They stand up to ask POI [Point of Information] so I don't see them. Then if you memorize what you say, you will lose everything. My teacher in debate said I should not to read what I write, only see it or, or glance sometimes. Okay, the next time, I memorized what I will say but she said, I must to look at the audience, I must not to close my eyes. So the next round, I'm improving and improving. Although I talk under time like only three minutes [7 minutes by rule], but I not close my eyes anymore. Then I also answer POI and I like it. I'm not afraid anymore like before in my first time.

Indeed, communication and critical thinking are the two soft skills commonly identified as the top benefits of debating in the previous literature (Akerman \& Neale, 2011; Bellon, 2000; Darby, 2007; Goodwin, 2003; Hall, 2011; Inoue \& Nakano, 2004; Kennedy, 2003 and 2009; Lieb, 2007; Scott, 2008; Yang \& Rusli, 2012).Not only Job and Myo did present the relationship between communication and critical thinking skills but also Chatri, a debate student from Thailand.

During the debate, you will learn how to solve a problem and how you communicate with others. I have no chance like this before in my high school so I am afraid to say what I think. But in debate class, I learn to say my opinion and present my ideas and what I read when I prepare for the debate.

In the preceding excerpt from Chatri, communicating and thinking critically go simultaneously showing the cognitive complexity of debate as an activity. He also needed to remember what he read during the preparation time to present at the actual debate when he speaks and, of course, listens to his opponents. Debaters also outline their points by writing notes during the preparation stage. Thus, there is an integration of skills that Brown $(2004,2007)$ suggests for communicative language teaching and learning as well as task-based language teaching, i.e. integrating the four macroskills (listening, speaking, reading and writing) when teaching the target language. Not only Job and Myo did present the relationship between communication and critical thinking skills but also Chatri, a debate student from Thailand.

During the debate, you will learn how to solve a problem and how you communicate with others. I have no chance like this before in my high school so I am afraid to say what I think. But in debate class, I learn to say my opinion and present my ideas and what I read when I prepare for the debate.

In the preceding excerpt from Chatri, communicating and thinking critically go simultaneously showing the cognitive complexity of debate as an activity. He also needed to remember what he read during the preparation time to present at the actual debate when he speaks and, of course, listens to his opponents. Debaters also outline their points by writing notes during the preparation stage. Thus, there is an integration of language skills that Brown (2007) suggests for communicative language teaching and learning as well as task-based language teaching, i.e. integrating the four macroskills (listening, speaking, reading and writing) when teaching the target language.

The international review of Akerman and Neale (2011) on debate reported that several authors attribute the academic benefits of debate to its interactive nature which means that learning is socially constructed rather than just taught. Thus, this interactive nature embeds critical thinking skill in the form of argumentation and communication skills making these two skills inseparable like twins as it is not possible to debate without critically thinking while delivering a speech at the same time making students practice complexity of language use. In debate, students orchestrate at the 
same time ideas, organization, vocabulary, grammar, debate techniques or in short, matter, manner and method as the criteria in judging a debate. It is indeed a complex activity that can help students with complex communication and problem-solving tasks in the real world. Debate's very important feature is for students to propose a solution to a problem, to argue why such a solution works better than any other solution or to judge the value or the principle of a given problem, thus it necessitates the higher order skills in Bloom's Taxonomy of Learning.

\subsubsection{Moving beyond the Language Learning Plateau}

Ellis (2003) points out that language learners need to solve a problem and practice complex language functions like they use the language in the real world. Chatri, a Thai student from Bangkok, shared his experience about learning English communication skills implying his need for a more complex and challenging communication activities other than just games back in high school as follows.

When I was in high school, I hate my teachers in English always playing game all the time. I could not learn much in playing only in the class like the teacher was lazy and teach us very simple. But in debate, we have to think a lot and speak very long and response to the POI [point of information]. It's very good way to learn real communication and best way of thinking solution for problem. Analysis is very important for every human and debate will teach you how to analysis, how to solve your problem very fast and speak more effectively, not slow and broken, so you convince your adjudicator about your points.

What Chatri said here is very relevant to classroom pedagogy particularly in language teaching when playing games is involved. While playing game is a fun way of teaching language, it could not occupy all the learning time particularly for advanced students who need more challenging lessons so they would not plateau in their learning (Richards, 2008). To move beyond the language learning plateau, Richards suggested that language learning activities should be challenging and motivating for students. In addition, Munzenmaier (2013) suggests that Bloom's Taxonomy be fully used in any classroom activity if meaningful and useful learning is desired. If the learning objectives of having the learners play a game in the classroom do not conform to Bloom's Taxonomy particularly in language learning, it is most likely that the game is just filling in the time just like what Chatri described. Chatri claimed that debate is a good way to learn communication skills as it requires a great deal of critical thinking skills. Games can be put in their proper place like just for a point of motivation or for practice of a certain language function developed in a lesson. For Chatri, communication involves responding to interlocutors such as answering Point of Information (POI) which uses analytical skills at the same time improving fluency in speaking.

\subsubsection{Developing Fluency}

Chatri mentioned in the above excerpt the need to speak not only effectively and convincingly but also fluently, with less hesitations or big gaps. All the FG participants see pressure as a positive feature of debate to push them to develop fluency except for Intan from Indonesia who has the reservation that other students, not she herself, might see debate as threatening. She said, "I feel that other students are afraid because we need to speak our points quickly when we debate." Andre also from Indonesia, however, countered Intan's point by saying, "That pressure makes debate really challenging, together with POI. Eric has a very good point to share in terms of how debate can develop fluency in communication skills by debating.

Debate is a very good practice of fluency in speaking English. In general, it's actually where I developed my communication skills in English. As a debater, I've gotta speak fast so I can say more points and support my arguments with more evidences. If I speak slowly, I can say just a few things that's why fluency can really be developed if you debate a lot.

Indeed, debate as a pedagogical tool serves its purpose well in the EFL/ESL classroom as memorization or rote learning is not encouraged but meaningful communication particularly during the debate task as set by the debate rules that debaters should engage with their opponents well specifically in both POI and rebuttals. As Myo described, it is not possible for him to just deliver a memorized speech as there is a necessity to interact not only with the audience but more importantly with his opponents particularly in addressing Points of Information or POI.

\subsubsection{Challenging and Engaging POI and Rebuttals}

The participants of this study claim that POI is the most challenging part of the debate as they would not be able to determine what point would be exactly raised by their opponents yet they need to address it on the spot during their speech; otherwise, they would lose points for not engaging with their opponent. For example, Andre said, "What I like most about this debate is the POI because asking and answering question smartly in just seconds, within the allowed time, is so challenging." Like what Myo described here, the POI in the parliamentary debate format like the All-Asians used in this study does not make memorization of speech possible because, as Myo explained, the debaters would be lost in their memorized speech once they get interrupted with a POI. Andre implied that POI is challenging because the speaker may be disrupted anytime during his speech to answer a POI raised and this will distort the flow of any prepared speech but will make the debaters alert to focus. Besides, debaters could not prepare ahead of time for a memorized rebuttal as they would not be able to predict exactly what arguments their opponents would deliver. Although participants do not see rebuttals as challenging as POI as they do not rebut outright, they need to engage with their opponents through the 'destroy-build' principle by which they need to weaken the points of their adversary during their own speech before they can build their own case as the debate rules govern them. 
This interactive nature of debate suits the EFL/ESL classroom quite well because in the real world, memorized speech is not the norm as people interact with each other in a spontaneous way not with a note to read all the time. As the debate class in this study was offered to EFL students with higher listening and speaking scores, if they are allowed to prepare their speech and just read it, they would not be able to improve their communication skills. Richards (2008) suggested that for advanced learners not to plateau in their language proficiency, they should be provided learning that would make them level up. If they would be allowed to deliver a memorized speech, they would not learn how to interact and would not improve their fluency. In the real world, no one goes out with a piece of paper to read while communicating with someone.

Language tasks in the classroom should resemble how the target language is used in the real context outside the learning environment (Brown, 2004; Ellis, 2003). In this case, debate as a pedagogical tool with an interactive nature prepares students to be communicative in the $21^{\text {st }}$ century job market when communication is of utmost importance in presenting ideas and answering on-the-spot questions that may arise during such presentations. Just like what Job said, no matter how good the preparation of the set of arguments would be if the debaters are not able to communicate their ideas clearly and effectively, they would still lose. Even in a job interview, the job applicant should be able to answer questions spontaneously. In the same way, even if engineers and entrepreneurs have brilliant plans and ideas but they are not able to communicate them well with their teammates and to their stakeholders to make their ideas tangible, such plans will not work as they cannot operate in a vacuum.

\subsubsection{Intrinsic and Extrinsic Motivation}

The participants find debate as challenging. Motivation could either be one based on intrinsic interest in the activity itself or on the extrinsic rewards by the activity. In the Self-Determination Theory, Ryan and Deci (2000) believe that intrinsic motivation is based on innate needs for self-determination and competence, i.e. people perform an activity they find interesting and challenging. By rising above the challenges, students develop a sense of competence and confidence in their abilities and this makes them determined to learn. This intrinsic motivation is shown by the participants like Andre, Myo and Chatri who described the challenge they encounter during the debate particularly answering POI.

Both debate experts and debate students expressed how debate developed their English communication skills which they think could be useful in their job. For example, Joyce who used to be a student in debate back in her high school shared her debating experience as regard the need of presentation skills in English.

Debating has helped me a lot because before this, whenever I would do a presentation during my secondary school, it was usually in Bahasa Melayu. I seldom did a presentation in English. But because I'm taking engineering course it is really essential to do a presentation in English language.

Joyce saw the need of English communication skills thus she further developed it by joining the university debate. The following excerpt shows Joyce's extrinsic motivation.

Before I joined the debating club, I fetl I'm not confident talking in English. I was not confident to present my point in English because I seldom spoke it. It's like it's my third language because my first language is my native tongue, Kadasan. My second language is Bahasa Melayu, of course. And my third one is English. And during my secondary school, I only used it during my English classes. I was lucky to have a teacher who forced us to debate in English so it gave me a good practice of my little English that time. So when I went to the university I came to think that I need to learn to speak very confidently in English. So, I joined the debating in English and it actually helped me improving a lot in my communication skills because in debating you need to prepare well and you have the stage to tell people your point about the topic. And then during your speech, there will be some points of information from your opponents that you need to answer right away. I feel amazed that whenever I deliver my speech during the debate, I can answer the questions. During the presentation, it is an essential skill to answer the POIs or questions.

From what Joyce stated above, she manifested both intrinsic and extrinsic motivation in that, she felt the need to develop her confidence in speaking and in answering POIs quickly aside from the reward she links with her being an engineer. Debate, therefore, is a good platform for learning English in an ESL/EFL context. It is a good activity to practice English in a country where English is not used outside the classroom as it gives the students motivation to use English in a natural way. In fact, Joyce even recognized her English teacher's enforcement to let her class debate in English as she realized that it gave her a good practice of the language she considers important in her success as an engineer especially in presentations. Developing confidence for speaking in front of an audience is one of the extrinsic rewards that debate students recognize as they seldom have the opportunity to practice public speaking and much more something that involves serious critical thinking using a borrowed language. Andre shared his personal experience on how he developed his communication skills by the strictly time-limited debate.

During the debate itself, I believe it's more on developing communication and critical thinking skills. Imagine you speak for seven minutes and yeah, sometimes more than that. I always do that speaking beyond the time limit (laughs) especially if there are POIs. That's where I can practice my critical thinking more and speaking with the pressure especially if the POI or the question is something you have not prepared for.

The time pressure is considered by students as a good motivation for them to practice their communication skills within limited time. This can be related to Dornyei's (2001a, 2001b) language learning motivation theory in which learners 
could be motivated by challenging activities. If the activity is too easy, students would not be interested in learning so the time pressure could push them to perform because they are challenged.

\subsubsection{Learners' Autonomy Development}

The participants say almost the same thing on how debate can develop communication skills in English. What is very interesting in what they say in common is what they perceived as the enforcement by their teacher to use debate and not to read their notes all the time when debating. Indeed, developing learner's autonomy is very important. If the debate students were just allowed to read from their notes all the time, they would not develop fluency and confidence in using English as it is not their first language. It might be difficult at first for them to speak without reading their notes all the time but the encouragement of their teacher that they can do it without their prepared notes would help a lot in developing autonomy. Myo and Intan proved it to themselves that they could speak in front of many people without depending on their notes anymore by means of practice through the debates. Like Joyce, they attribute to the debate format, specifically to the POI, their big improvement in their English communication skills as well as critical thinking skills.

Myo reported a big improvement of his communication skills by not relying anymore on his memorized speech which he said the reason why he had to close his eyes to remember his next line but he realized that he could not interact with his opponents if he continued doing this. The development of learner autonomy in the EFL/ESL classroom is the achievement of optimum success in language learning and this is made possible by debate as a pedagogical tool. The pedagogical design gives students ample preparation time to research and brainstorm about their topic as well as to learn new vocabulary and rehearse their language before they perform on stage for the actual debate. They also get immediate feedback after the debate on their performance including comments and suggestions how they can improve their communication skills. Thus, debate as a pedagogical tool can develop learners' autonomy in their English communication skills.

Akerman and Neale (2011) identified communication and argumentation skills as a key finding which includes improved English when it is not the students' first language as evidenced by the study of Inoue and Nakano (2004) in Japan. Communication and speaking skills was perceived by students as the most important benefit of competitive debate in the surveys conducted in the US (Williams, McGee, \& Worth, 2001; Littlefield, 2001). As the goal of this study is to introduce debating in the classroom in the ASEAN context, Cronin's (1990) study found that 74 percent of students from six university classes in the US indicated communication skills as the top benefit of debating. Not only should communication skills be taught resembling the way it is used in the real world but also the way it is demanded when students go out of the university to perform their job in the demanding workplace. Eric expressed the demand of communication skills in every day life once students go out in the real world of work. He said, "A lot of things taught in college have no real use at work. But communication skills, these are the things that get you at work, these are the things you need at work."As an advocate of debate training not only students but also teachers to become debate trainers and coaches, Eric is very much aware of the role of communication skills in both getting and performing a job and he believes that debate can develop it the way he was developed. He believes that debate can benefit more students if it is indeed introduced in the wider scale, i.e. in the classroom as a requirement as proposed by Bellon (2000) and Snider and Schnurer (2006). Like the other participants of this study, Eric strongly believes in the power of debate to develop communication skills especially at the while-debate stage.

\subsection{Post-Debate Stage}

The post-debate stage which was not given attention in the previous studies on debate is still important for the participants of this study to learn communication skills particularly on the aspect of listening from the adjudicators for the corrective feedback. It is considered by the participants as the evaluation of their performance and by listening to the adjudicators' comments and suggestions, they can learn and improve. Thus, listening as well as asking questions and interaction is given primary attention at this stage. While reading and writing are for the pre-debate stage, speaking is for the actual debate stage, listening is for the post-debate stage.

\subsubsection{Learning from Listening and Interaction with Others}

Job explained the meaning of communication skills and how it is practiced at the post debate stage.

Communication skills is not just about speaking. It's also about listening. It's also about being able to receive information. It's also being able to process information and translate them into something that you know you can use in the future. So, I think communication skills is also being enhanced during the post-debate skills. Again, number 1, because the judges provide criticisms so they have to listen. Number 2, because debaters are given the chance to ask questions so they have to also practice communication skills. Number 3, they have to be able to still interact with each other as a team so that they communicate with each other. And also they can interact now with their opponents. So, I think their communication skills are also being enhanced right after the debate or during the post-debate.

Job described the process of communication in terms of listening that involves receiving and processing of information and translating it into something beneficial. Moreover, Job also mentioned about the chance given to debaters to ask questions and interact with their team-mates and with their opponents at the post-debate stage. In the interaction model of language teaching, interactions of teachers with their students or among small group of students help learners perform better academically as genuine dialogue or interactions are more beneficial than traditional teacher-centered 
classrooms. Interaction model facilitates language learning of students rather than control it while it encourages the development of higher-order cognitive thinking skills (Levine \& McCloskey, 2013).

From the perspective of debate students, Intan also highlights the importance of learning by listening to the adjudicators.

We listen to our adjudicator for her comments, her suggestions how we can improve next time or next debate. It's also important to listen because if we don't listen, we will not improve. We do the same mistake in the next round and we get low grade (laughs). We don't develop as a debater. So listening is very important.

Intan recognizes the importance of communication skills in terms of listening to the adjudicators which she viewed as a source of learning. In the Input Hypothesis by Stephen Krashen (1987), language input from listening or reading is considered very important in learning the target language. Krashen states that the best language input $(i)$ is something that is understandable by the language learners but should be a step beyond their current level of understanding or competence $(i+1)$. As Krashen encourages a natural way of using the language, the teacher's role is to provide enough input, i.e. many opportunities that will make the students interact with each other in a given context that promotes understanding and use of language. The communication activities should include negotiation of meaning for students to practice more complex structures and thus continue the language acquisition process. If better and more outputs are desired, more inputs should be provided and debate qualifies as an abundant input for learning language from predebate to post-debate stages. Krashen considers comprehensible input the most important part of any language teaching program so debate should be introduced in EFL/ESL classrooms to provide more meaningful inputs for students who have less opportunities in practicing English.

\subsubsection{Improving from Immediate Corrective Feedback}

A very important aspect of debate as a pedagogical tool is what the participants of this study consider as the exciting part of the post-debate stage, the oral adjudication or the corrective feedback. The oral adjudication is always awaited by the debaters after the debate. For example, Sonya said that debaters need feedback right after the debate while what all they said are still fresh because it is where they can improve. However, Sonya suggested that for oral adjudication to be more helpful in terms of language development if debate is to be introduced in the classroom, more time should be given to focus on this aspect especially for students who need more improvement in terms of their grammar, pronunciation, etc. Nisa, a Thai student debater, supports this suggestion.

We learn a lot from the oral adjudication. We improve our debating, our techniques, if we follow what our debate teacher say after the debate. But I think we can't improve our grammar and pronunciation much because we always lack time for all the comments so English cannot be given attention. The teacher tells us who win and why or who is the loser and why they lose so focus of comments is more on the matter or the arguments and method of debate but not much in manner, just some corrections. But sometimes we go see our teacher in her office to ask her feedback in our manner and it helps.

What Nisa said bears great relevance in terms of pedagogy if debate will be used in the EFL/ESL classroom. From the perspective of the participants, immediate feedback can improve learners. However, if students would not see the teacher as adjudicator for personal feedback, they would not improve in their language errors in terms of grammar and these errors may be fossilized. Thus, Sonya's suggestion needs to be taken if debate as a pedagogical tool would be practiced in its entirety in the EFL/ESL classroom to develop not only fluency in speaking, listening, reading and writing but also accuracy. As mentioned earlier, the focus of CLT is on meaning but in task-based language teaching, form has its place and in the case of debate as a pedagogical tool, corrective feedback on form can be handled more deliberately at the post-debate stage. With the time constraint issue presented by the participants themselves, additional feedback time could be offered after class.

\section{Conclusion}

The findings show that debate can, indeed, develop communication skills particularly in English, which are consistent with the previous studies. For example, the study of Inoue and Nakano (2004) comparing between NDT-style and parliamentary debate (PD) style which is similar to the style used in this study, PD turned out to be developing English communication skills better than NDT due to its focus which is more on communication rather than on argumentation. Inoue and Nakano's subjects reported that debate made them get used to the English language and acquire "various skills in English." However, since their study used mixed-method, there are less qualitative descriptions as to how their respondents develop English communication skills. In this study, the participants described how debate can develop listening, vocabulary and fluency in speaking using the international language. This study contributes to the existing body of knowledge on debate particularly on how each of the three stages of All-Asians parliamentary debate can develop communication skills among EFL/ESL students.

Akerman and Neale (2011) claimed that debate as an activity necessarily involves oral communication, thus it leads to the development of communication skills. They also pointed out that it can improve English if it is not the students' first language. Indeed, the findings of this study have practical implications for EFL/ESL contexts when students lack the platforms to practice their English in a more meaningful and critical way. For example, Prasit from Thailand recognized this need but he acknowledged how debate is able to provide a good way to naturally use English especially for novice debaters like the FG participants of this study who are still struggling with their English. Although the ESL contexts of Malaysia and the Philippines are supposed to provide an advantage for language learners, Sonya, Joyce and Eric recommend the use of debate in the classroom as they believe that students do not get enough communicative practice 
of English inside and outside the classrooms. They also observed that debate is offered to just a few students for competitive debating and these are usually the students who are already advanced in their communication and critical thinking skills. Indeed, communicating effectively is not just speaking fluent English but also speaking logically at the right time with substance, supported with evidences and this is a critical aspect learned by debating. Speaking and listening are the two communication skills used in everyday workplace, thus they have to be enhanced well before students go out of the university and debate can be a pedagogical tool to teach such skills.

The findings of this study is similar to Scott's (2008) who found out that debating engages the learner in the activity allowing teachers to create a learning environment that helps students to move away from being just knowledge receivers such as in lecture but to make them active participants in the learning process. Musselman (2004) also observed that using debate as a pedagogical tool in the classroom develops actively engaged students making them empowered and autonomous and responsible over their own learning. The participants of this study portrayed the use of the pre-debate stage for the brainstorming that engage the team members with each other, the actual debate for the POI and rebuttals that actively engage the students with their opponents, and the post-debate stage that engage all the debaters with the adjudicators, their team-mates and their opponents. This pedagogical aspect focusing on the three stages of the debate was not dealt with in the previous studies on debate.

The use of English to teach English characterizes the strong version of CLT, the same feature that Krashen (1987) recommends to be practiced in the language classroom. This concept is particularly more helpful for students like the participants in this study who already have certain level of English proficiency and what they need is to operationalize their basic knowledge or competence of the language to make it functional, i.e. the actual use of the language in communicating with others. A very important finding in this study related to SLA and language learning is how debate can dramatically develop students' vocabulary at the pre-debate stage which they said they practice during and after the debate. This relates to Schmidt's Noticing Theory in that debaters give attention to new language features such as vocabulary and grammar they encounter while they read then use them and later become part of their interlanguages. Therefore, debate is more appropriate for university students across the ASEAN countries as they have been learning English since elementary and it is in college that they need more motivating and challenging language activity that will fully develop both their language and higher order thinking skills for a more effective communication skills.

Debate is a pedagogical tool that fits well in the Communicative Language Teaching (CLT) paradigm. CLT is learnercentered, cooperative, interactive, holistic and task-based. Indeed, these characteristics are reflected on debate as described by the participants of this study. As a team activity, debate is cooperative and it empowers the learners to be responsible of their learning and to be autonomous in their language use. Debate, therefore, is learner-centered and highly interactive as opposed to traditional teaching methods such as lecture. Debate as a pedagogical tool focuses on the meaning of communication although form is not ignored as comments are given in terms of the matter, manner and method of debate discussed at the post-debate stage aimed at improving these three debate aspects including language. It is a fun and challenging activity for EFL/ESL students to further develop their communication skills so that they will not plateau in their language learning. However, more time should be allotted for the corrective feedback on the aspect of language use at the post-debate stage so that students will not fossilize their errors and that a good balance between fluency and accuracy for an effective and meaningful communication will be achieved.

\section{References}

Akerman, R. \& Neale, I. (2011). Debating the evidence: An international review of current situation and evidences. Retrieved April 30, 2013 from http://debate.uvm.edu/dcpdf/ESU_Report_debatingtheevidence_FINAL.pdf.

Bellon, J. (2000). A research-based justification for debate across the curriculum. Argumentation \& Advocacy, Winter, $36(3), 161-175$.

Baxter, P. \& Jack, S. (2008). Qualitative case study methodology: Study design and implementation for novice researchers. The Qualitative Report, 13 (4), 544-559. Retrieved on June 3, 2013 from http://www.nova.edu/ssss/QR/QR13-4/baxter.pdf.

Boeije, H. (2010). Analysis in qualitative research. USA: Sage.

Brown, H. D. (2007). Teaching by principles: An interactive approach to language pedagogy. USA: Longman.

Brown, H. D. (2004). Principles of language learning and teaching. USA: Longman.

Clavel, T. (2014, January 19). China, South Korea face familiar woes in English quest. The Japan Times. Retrieved on March, 21, 2014 from http://www.japantimes.co.jp/community/2014/01/19/issues/china-south-korea-face-familiarwoes-in-english-quest/\#.U9rlRPmSySo

Creswell, J. W. (2012). Educational research: Planning, conducting and evaluating quantitative and qualitative research. USA: Pearson.

Creswell, J. W. (2013). Qualitative inquiry \& research design: Choosing among five approaches. USA: Sage.

Creswell, J.W. (2014). Research design: Qualitative, quantitative, and mixed methods approaches. USA: Sage Publications.

Cronin, M. (1990). Debating to learn across the curriculum: Implementation and assessment. Paper presented at the Southern States Communication Association Convention, Birmingham, Alabama. 
Darby, M. (2007). Debate: A teaching-learning strategy for developing competence in communication and critical thinking. Journal of Dental Hygiene, Fall, 81 (4), 78.

Deci, E. \& Ryan, R. (2000). The "what" and "why' of goal pursuits: Human needs and the self-determination of behavior. Psychological Inquiry. 11 (4), 227-268.

Denzin, N. K. \& Lincoln. S.Y. (2005). Qualitative research. Thousand Oaks, California, USA: Sage Publications.

Dörnyei, Z. (2001a). Motivational strategies in the language classroom. Cambridge:

Cambridge University Press.

Dörnyei, Z. (2001b). Teaching and researching motivation. Harrow, Essex: Pearson.

Ellis, R. (2003). Task-based language learning and teaching. UK: Oxford.

Freeley, A. \& Steinberg, D. (2012). Argumentation and debate. USA: Wadsworth Cencage Learning.

Goodwin, J. (2003). Students' perspectives on debate exercises in content area classes. Communication Education, 52 (2), 157-163. Retrieved on April 29, 2013 from www.goodwin.public.iastate.edu/pubs/goodwinstudents.pdf.

Hadley, A. O. (2000). Teaching language in contexts. USA: Cencage Publishing.

Hall, D. (2011). Debate innovative teaching to enhance critical thinking and communication skills in healthcare professionals. The Internet Journal of Allied Health Sciences and Practice. Retrieved on May, 9, 2013 from: http://ijahsp.nova.edu/articles/Vol9Num3/pdf/Hall.pdf

Hancock, D. R. \& Algozzine, B. (2006). Doing case study research. USA: Teachers College Press.

Hardman, J. (2008). Researching pedagogy: An activity theory approach. Journal of Education, 45, 65-95.

Inoue, N. \& Nakano, M. (2004). The benefits and costs of participating in competitive debate activities: Differences between Japanese and American college students. Paper presented at Wake Forest University/International society for the study of argumentation, Venice argumentation conference, June 27-30.

Kennedy, R. (2009). The power of in-class debates. Active Learning in Higher Education, 10 (3), 225-236. Retrieved June 3, 2013 from alh.sagepub.com/content/10/3/225.full.pdf.

Krashen, S. (1987). Principles and practices in second language acquisition. New York: Prentice-Hall.

Krashen, S. (1993). The power of reading: Insights from the research. Englewood, Co.: Libraries Unlimited.

Krefting, L. (1991). Rigor in qualitative research: The assessment of trustworthiness. The American journal of occupational therapy. March 1991, Volume 45(3), pp. 214-222. Retrieved on February 1, 2013 from http://portal.limkokwing.net/modulemat/rigor\%20in\%20qualitative\%20research\%20trustworthiness\%20test(1).pdf.

Krueger, R.A. (2002). Designing and conducting focus group interviews. Retrieved March 16, 2013 from http://www.eiu.edu/ ihec/Krueger-FocusGroupInterviews.pdf.

Levine, L.N. \& McCloskey, M. (2013). Teaching English language and content in mainstream classes: One class, many paths. Boston, MA, USA: Pearson.

Lieb, M. (2007). Teaching debate skills to intermediate and lower level EFL students. Retrieved May 15, 2013 from www.tht-japan.org/proceedings/2007/m_lieb73-84.pdf.

Littlefield, R. (2001). High school student perceptions of the efficacy of debate participation. Argumentation and Advocacy, 38 (2), 83-97.

Munzenmaier, C. (2013). Bloom's taxonomy: What's old is new again. The Learning Guild Research. Retrieved May 15, 2014 from http://www.lessonpaths.com/learn/i/information-literacy-issues/blooms-taxonomy-whats-old-is-newagain-2.

Musselman, E. (2004). Using structured debate to achieve autonomous student discussion. The History Teacher, 37 (3), 335-349.

Parcher, J. (1998). The value of debate: Adapted from the report of the Philodemic Debate Society, Georgetown University, Published April 1, 1999, 3-7. Retrieved May 4, 2013 from http://www.tmsdebate.org/main/forensics/snfl/debate_just2.htm.

Patton, M. (1990). Qualitative evaluation and research methods. Beverly Hills, CA: Sage.

Patton, M. (2002). A guide to using qualitative research methodology. Medecins Sans Frontiers. Retrieved February 14, 2014 from http://fieldresearch.msf.org/msf/bitstream/10144/84230/1/Qualitative\%20research\%20methodology.pdf.

Richards, J. and Rodgers, T. (2001). Approaches and methods in language teaching. UK: Cambridge University Press.

Richards, J. (2008). Moving beyond the plateau: From intermediate to advanced levels in language learning. USA: Cambridge University Press.

Rosero, E.V. (2012, March 3). Why many fresh college grads don't get hired, according to survey of managers. GMA News Online. Retrieved June 3, 2013 from: http://www.gmanetwork.com/news/story/250239/economy/business/whymany-fresh-college-grads-don-t-get-hired-according-to-survey-of-managers.

Rudestam, K. E., \& Newton, R. R. (2007). Surviving your dissertation. USA: Sage. 
Ryan, J. (2009). The three fundamentals of effective leadership. Retrieved June 15, 2014 from

http://www.forbes.com/2009/04/29/vision-communication-judgment-leadership-managing-ccl.html.

Scott, S. (2008). Perceptions of Students' Learning Critical Thinking through Debate in a Technology Classroom: A Case Study. Journal of Technology Studies, 34 (1), 39-44.

Shakir, R. (2009). Soft Skills at the Malaysian Institutes of Higher Learning. Asia Pacific Education Review Springer Vol.10 No. 3 pp309-315. Retrieved April 29, 2013 from www.eric.ed.gov/?id=EJ850588.

Snider, A. \& Schnurer, M. (2006). Many Sides: Debate Across the Curriculum. USA: IDEBATE Press.

Stake, R. (2005). Qualitative case studies. In Norman K. Denzin \& Yvonna S. Lincoln (Eds.), Qualitative research ( $3{ }^{\text {rd }}$ ed.). 433-466. Thousand Oaks, CA: Sage Publications.

Sternberg, R. J. (1987). Most vocabulary is learned from context. In M. G. McKeown \& M. E. Curtis (Eds.), The nature of vocabulary acquisition, 89-105. Hillsdale, NJ: Lawrence Erlbaum Associates.

Sulaiman, Y., Fauziah H., Wan Amin \& Nur Amiruddin (2008). Implementation of generic skills in the curriculum.

Edith Cowan University Research Online.Tracy, S. J. (2013). Qualitative research methods.UK: Wiley-Blackwell.

The Nation. (2013, November 7). Thailand ranks near the bottom in English proficiency: survey. Retrieved January 13, 2014 from http://www.nationmultimedia.com/business/Thailand-ranks-near-bottom-in-English-proficiency-30218895.html.

Wilkins, D. (1987). Linguistics in language teaching. London: Edward Arnold.

Williams, D., McGee, B. and Worth, D. (2001). University student perceptions of the efficacy of debate participation:An empirical investigation. Argumentation and Advocacy. 37, 198-209.

Yang, C. H. \& Rusli, E. (2012). Using debate as a pedagogical tool in enhancing pre-service teachers' learning and critical thinking. Journal of International Education Research - Second Quarter 2012. The Clute Institute. Retrieved May 13, 2012 from eric.ed.gov/?id=EJ982692. 